\title{
Effect of Casein Phosphopeptide-Amorphous Calcium Phosphate on Fracture Resistance of Reattached Tooth Fragments Using Conventional and Self-Adhesive Bioactive Flowable Composite
}

\author{
${ }^{1}$ Oral and Dental Disease Research Center, Department of Operative \\ Dentistry, School of Dentistry, Shiraz University of Medical Sciences, \\ Shiraz, Iran \\ ${ }^{2}$ Department of Pediatric Dentistry, School of Dentistry, \\ Shiraz University of Medical Sciences, Shiraz, Iran
}

Maryam Firouzmandi ${ }^{1} \quad$ Neda Afzali ${ }^{2}$ Zahra Parsaie ${ }^{2} \quad$ Najmeh Mohammadi $^{2}$

\begin{abstract}
Address for correspondence Najmeh Mohammadi, DMD, MSc, Department of Pediatric Dentistry, School of Dentistry, Qasrodasht St., Shiraz, 71956-15878, Iran (e-mail: najme_mohammadi64@yahoo.com).
\end{abstract}

Eur J Dent 2020;14:288-293

\begin{abstract}
Objectives The present study aimed to investigate the effect of casein phosphopeptide-amorphous calcium phosphate (CPP-ACP) complex and the type of flowable composite (conventional or self-adhesive bioactive) on the fracture resistance of fractured incisors restored through reattachment technique.

Materials and Methods In this experimental in vitro study, 60 extracted bovine central mandibular incisors were randomly divided into six groups $(n=10)$ according to the reattachment technique. Their incisal edges were cut off to represent an enameldentin fracture. The fragment edges were reattached as follows: Group 1-selective etching and bonding followed by conventional flowable composite; Group 2-selective etching and bonding followed by bioactive flowable composite; Group 3 was like Group 2 but without applying bonding; Groups 4, 5, and 6 were similar to Groups 1, 2, and 3, respectively, but both tooth fragments were pretreated with CPP-ACP-containing paste for 3 minutes. Fracture resistance was assessed by a universal testing machine.

Statistical Analysis Data were analyzed by SPSS-Statistical Package for the Social Sciences-software using one-way analysis of variance and Tukey post-hoc tests $(\alpha=0.05)$.

Results The highest and lowest fracture resistance was recorded in Groups 5

Keywords

- bioactive

- casein phosphopeptide-amorphous calcium phosphate

- fracture resistance

- reattachment technique (15.96 MPa) and Group 6 (1.95 MPa), respectively, being significantly different from the other groups. The mean fracture resistance of Groups 3 and 6 was significantly lower than the other groups $(p<0.05)$. However, Groups 1,2 , and 4 showed no difference in fracture resistance.

Conclusion Bioactive composite was not superior to conventional composite for fragment reattachment, but using it in self-adhesive mode reduced the fracture strength significantly. Yet, pretreatment with CPP-ACP, followed by application of adhesive, improved the fracture resistance of bioactive composite.
\end{abstract}

\section{Introduction}

Crown fractures of the permanent dentition are prevalent among school children (26-76\%) as a part of traumatic injuries. ${ }^{1}$ Generally, the anterior teeth are the most affected ones ( $80 \%$ central incisors and $16 \%$ lateral incisors) due to the position of the maxilla and protrusion of teeth. ${ }^{2}$ Restoration of the fractured teeth through reattachment of the intact 
tooth is the treatment of choice due to its total esthetical recovery, color stability over time, and wear at similar rate as other teeth. Besides being safe and simple, this conservative procedure requires less chair-time, which might reduce the treatment cost.-8 Yet, this method has several inherent drawbacks, the most important of which is the lower fracture resistance of the reattached tooth. It is reported that the mechanical strength of reattached tooth is 20 to $60 \%$ lower, depending on the bonding agent and restorative technique..$^{8-11}$

Based on a couple of clinical follow-ups, additional tooth preparations may not provide clinical success., ${ }^{90,12-14}$ Meanwhile, some others believe that simple reattachment by using adhesive systems without additional preparation does not recover the original mechanical strength. ${ }^{6}, 15$ Moreover, the reattached fragment is highly susceptible to detachment in case of a new trauma or excessive masticatory forces. ${ }^{1}$

The fragment retention may be affected by the restorative materials and the adhesive system used. The 10-methacryloyloxydecyl dihydrogen phosphate (10-MDP) monomer present in self-etch adhesives is capable of forming strong ionic bonds with the calcium in hydroxyapatite crystals, remaining around the collagen fiber due to the partial demineralization effect of self-etch adhesive system. ${ }^{16}$ According to Yoshida et al's study, the interaction of 10-MDP monomer and calcium generates a stable monomer-Ca salt, which is capable of producing strong bond to dentin. ${ }^{11}$ On the other hand, casein phosphopeptide-amorphous calcium phosphate (CPP-ACP) promotes the formation of hydroxyapatite crystals around the exposed collagen fibers. The (CPP-ACP) mechanism of action is to provide a reservoir of free calcium and phosphate ions to maintain a supersaturation mineralization state on the enamel surface. ${ }^{17}$ Therefore, applying CPP-ACP adds higher amount of these ions on the tooth surfaces, and consequently increases the bond strength. ${ }^{18}$

Activa BioActive-Restorative is a flowable resin-based composite, which incorporates components of glass ionomer and resin composite. Fluoroaluminum silicate particles and polyacid components undergo the acid-base setting reaction. ${ }^{19}$ The smart material of Activa has the potential of releasing and recharging significant amounts of calcium, phosphate, and fluoride from the saliva or in the presence of a source like CPP-ACP paste, and therefore stimulates the apatite formation. This dynamic role acts against the marginal microleakage and discoloration of the restoration margin and improves the mechanical properties. ${ }^{20,21}$ According to the manufacturer, Activa contains rubberized resin, which is tougher with shock-absorbing property and is claimed to be more fracture resistant than the conventional restorative materials. $^{22}$

So far, studies on reattachment technique have merely focused on the conditions of the storage medium of the fragment and preparation of the tooth. ${ }^{8,23}$ To the authors' knowledge, no study has ever investigated the effect of pretreatment of the fractured teeth fragments with calcium-containing materials along with application of bioactive composite materials. The present study was conducted to evaluate the effect of CPP-ACP and self-adhesive bioactive flowable composite on the fracture resistance of fractured teeth restored through reattachment technique. The null hypothesis is that: (1) reattachment of fractured incisors with bioactive composite would not yield higher fracture strength compared with the conventional composite, and (2) CPP-ACP treatment prior to reattachment would not increase fracture strength.

\section{Materials and Methods}

This experimental in vitro study was done on 60 extracted bovine central mandibular incisors (average age $2.5-3$ years), free of any crack, defect, or caries. The teeth were first disinfected in $0.5 \%$ chloramine-T for 1 week, and then stored in saline till used. The teeth were marked on the labial surface $4 \mathrm{~mm}$ apical to the incisal edge. Each tooth was cut perpendicular to its long axis by using a diamond disk ( - Fig. 1). Then, they were randomly divided into six groups (Groups $1-6 ; n$ $=10$ ) according to the reattachment technique. In Group 1 (conventional composite), the enamel of the tooth and the fractured segment was selectively etched for 15 seconds with phosphoric acid (Etch-Rite; Pulpdent, Watertown, Massachusetts, United States), rinsed with water for 30 seconds, and gently air-dried for 15 seconds. Then, the primer of Clearfil SE Bond (Kuraray; Okayama, Japan) was applied on the enamel and dentin with slight agitation ( 20 seconds) and air-dried for 10 seconds. The bonding

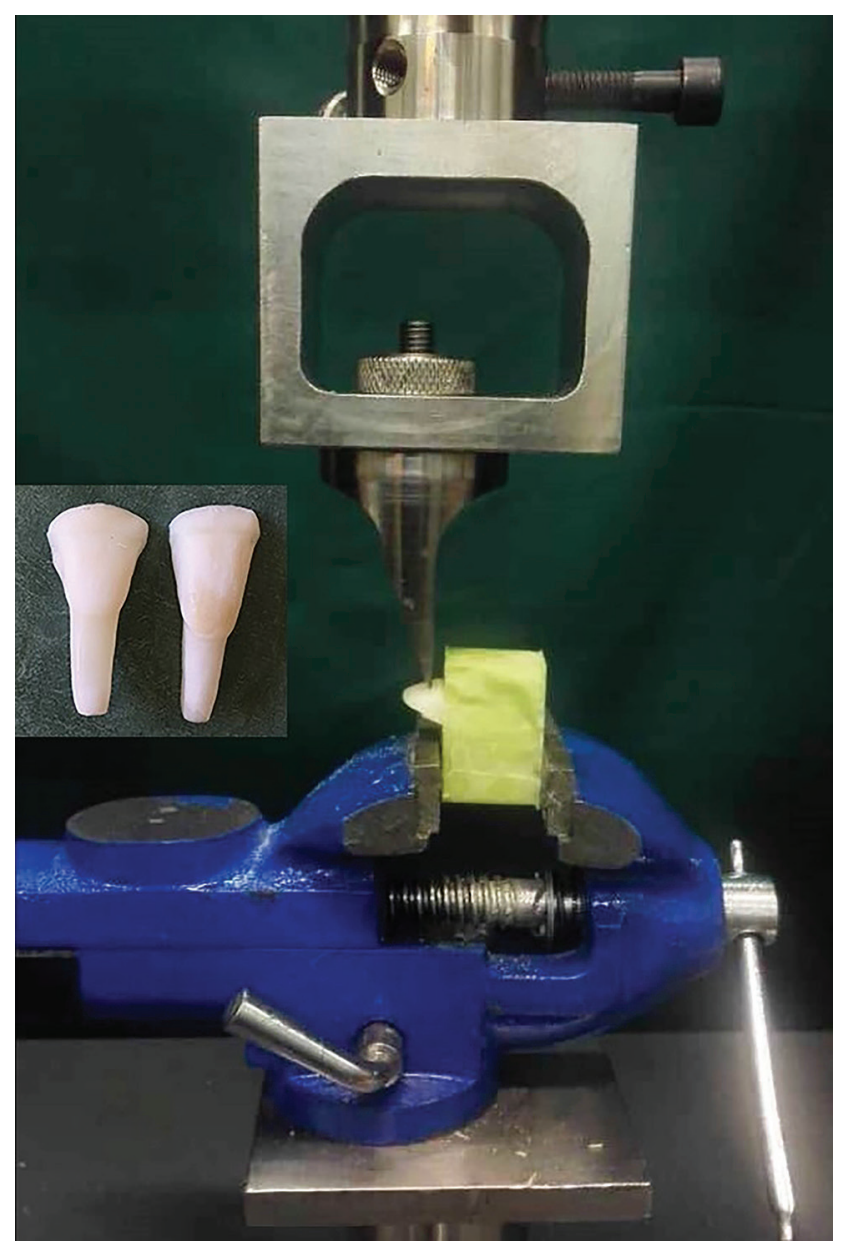

Fig. 1 Preparation of the specimens. 
agent of Clearfil SE Bond (Kuraray) was applied (15 seconds), air-thinned (10 seconds), and light-cured (20 seconds). For reattachment of the two segments, a thin layer of conventional flowable composite (Pulpdent; Watertown, Massachusetts, United States) was applied on both parts. The fractured segment was adapted on the tooth part and lightcured for 20 seconds from the buccal and lingual aspects. The excess composite on tooth surfaces was removed by using a scalpel.

In Group 2 (bioactive composite with bonding), the specimens were prepared just like Group 1, except for the conventional flowable composite, which was replaced with bioactive flowable composite (Activa BioActive; Pulpdent, Watertown, Massachusetts, United States). The reattachment technique in Group 3 (bioactive composite without bonding) was like Group 2 , but Activa was used as self-adhesive composite without etching and bonding. Reattachment in Groups 4 (CPP-ACP + conventional composite), 5 (СРP-ACP + bioactive composite with bonding), and 6 (CPP-ACP + bioactive composite without bonding) was similar to Groups 1, 2, and 3, respectively; they were only different in CPP-ACP pretreatment; that is, CPPACP (Recaldent, GC, Japan) was actively rubbed on both tooth fragments by using a brush for 3 minutes prior to adhesion.

- Table 1 summarizes the application of materials for groups of the study.

The specimens were embedded in acrylic blocks up to $1 \mathrm{~mm}$ below the fracture line, and the long axis of the tooth was parallel to the central axis of the block. The specimens were loaded on a universal testing machine (Zwick/Roell Z020; Zwick GmbH \& Co., ulm-Einsingen, Germany). The force was applied with a chisel-shaped tip, which was perpendicularly positioned on the fracture line on the facial surface of the crown, with the speed of $1 \mathrm{~mm} / \mathrm{min}$ until fracture occurred ( - Fig. 2 ). The force leading to fracture was measured in Newton. The area of the fracture surface was measured through planimetry to convert the Newton to Megapascal $\left(\mathrm{MPa}=\mathrm{F} / \mathrm{mm}^{2}\right)^{23}$
The failure modes were assessed by using $\mathrm{a} \times 10$ magnifier and classified as:

- Type I: adhesive failure in the tooth composite interface

- Type II: cohesive failure in the composite

- Type III: mixed adhesive and cohesive failure in the composite

- Type IV: mixed adhesive and cohesive failure in the tooth

Data were statistically analyzed using SPSS-Statistical Package for the Social Sciences-software (version 22, SPSS Inc.; Illinois, Massachusetts, United States). One-way analysis of variance (ANOVA) was used to find the effect of each variable, and Tukey post-hoc test was used for pairwise comparison of the study groups. The confidence level was $95 \%$, so $p<0.05$ was considered statistically significant.

\section{Results}

- Table 2 displays the results of the fracture test. The results of one-way ANOVA revealed significant differences among the study groups. The highest fracture resistance was recorded for Group 5 (CPP-ACP + bioactive composite with bonding: $15.96 \mathrm{MPa}$ ), which was significantly higher than the other groups. The lowest fracture resistance was observed in Group 6 (CPP-ACP + bioactive composite without bonding: $1.95 \mathrm{MPa}$ ). The results of Tukey post-hoc test showed that Groups 3 (bioactive composite without bonding) and 6 (CPP-ACP + bioactive composite without bonding) had significantly lower fracture strengths than the other groups $(p<0.05)$; however, these two groups were not significantly different in this regard $(p=0.206)$. No significant difference existed between Groups 1 (conventional composite), 2 (bioactive composite with bonding), and 4 (CPP-ACP + conventional composite). The prevalence of the failure modes is shown in - Table 2 . The most commonly occurring failure mode was adhesive failure.

Table 1 Summary of the materials used for the groups of the study

\begin{tabular}{|l|l|l|l|}
\hline Groups & Adhesive & Composite & Pretreatment \\
\hline Group 1 & Clearfil SE Bond (Kuraray, Okayama, Japan) & $\begin{array}{l}\text { Conventional flowable composite (Pulpdent, } \\
\text { Watertown, Massachusetts, United States) }\end{array}$ & None \\
\hline Group 2 & Clearfil SE Bond (Kuraray, Okayama, Japan) & $\begin{array}{l}\text { Bioactive flowable composite (Activa BioActive, } \\
\text { Pulpdent, Watertown, Massachusetts, United } \\
\text { States) }\end{array}$ & None \\
\hline Group 3 & None & $\begin{array}{l}\text { Bioactive flowable composite (Activa BioActive, } \\
\text { Pulpdent, Watertown, Massachusetts, United } \\
\text { States) }\end{array}$ & None \\
\hline Group 4 & Clearfil SE Bond (Kuraray, Okayama, Japan) & $\begin{array}{l}\text { Conventional flowable composite (Pulpdent, } \\
\text { Watertown, Massachusetts, United States) }\end{array}$ & $\begin{array}{l}\text { CPP-ACP (Recaldent, } \\
\text { GC, Japan) }\end{array}$ \\
\hline Group 5 & Clearfil SE Bond (Kuraray, Okayama, Japan) & $\begin{array}{l}\text { Bioactive flowable composite (Activa BioActive, } \\
\text { Pulpdent, Watertown, Massachusetts, United } \\
\text { States) }\end{array}$ & $\begin{array}{l}\text { CPP-ACP (Recaldent, } \\
\text { GC, Japan) }\end{array}$ \\
\hline Group 6 & None & $\begin{array}{l}\text { Bioactive flowable composite (Activa BioActive, } \\
\text { Pulpdent, Watertown, Massachusetts, United } \\
\text { States) }\end{array}$ & $\begin{array}{l}\text { CPP-ACP (Recaldent, } \\
\text { GC, Japan) }\end{array}$ \\
\hline
\end{tabular}

Abbreviation: CPP-ACP, casein phosphopeptide-amorphous calcium phosphate. 


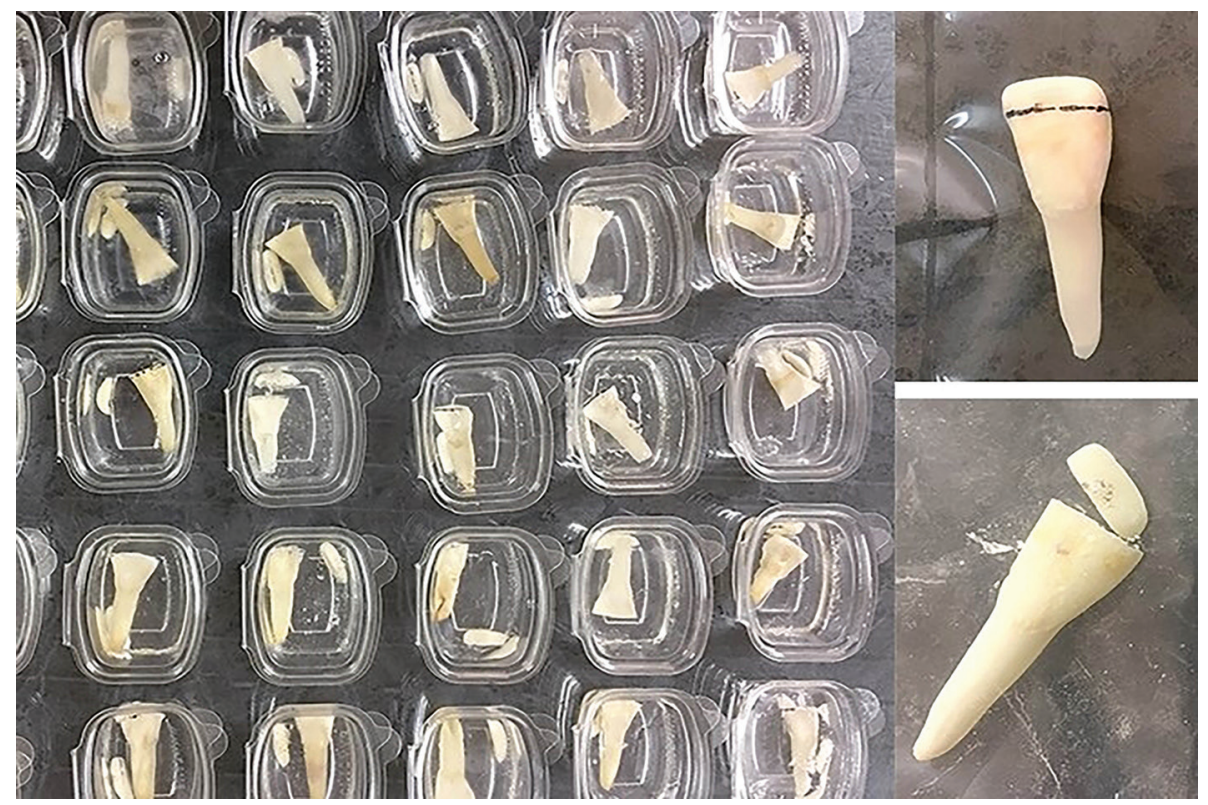

Fig. 2 Reattachment of fragment and specimens loaded on the universal testing machine.

Table 2 The mean fracture strength (MPa) and failure modes of the study groups

\begin{tabular}{|l|l|l|l|l|l|}
\hline \multirow{2}{*}{ Groups } & Mean (SD) fracture strength & \multicolumn{3}{|c|}{ Failure mode } \\
\cline { 3 - 6 } & & I & II & III & IV \\
\hline Conventional composite & $11.86(3.03)^{\mathrm{a}}$ & 4 & 2 & 4 \\
\hline Bioactive composite with bond & $12.14(1.46)^{\mathrm{a}}$ & 4 & 0 & 5 \\
\hline Bioactive composite without bond & $4.54(2.79)^{\mathrm{b}}$ & 8 & 0 & 1 \\
\hline CPP-ACP + Conventional composite & $12.29(1.36)^{\mathrm{a}}$ & 1 & 2 & 2 & 0 \\
\hline CPP-ACP + Bioactive composite with bond & $15.96(3.55)^{\mathrm{C}}$ & 3 & 0 & 1 \\
\hline CPP-ACP + Bioactive composite without bond & $1.95(0.49)^{\mathrm{b}}$ & 10 & 0 & 5 & 3 \\
\hline
\end{tabular}

Abbreviations: CPP-ACP, casein phosphopeptide-amorphous calcium phosphate; SD, standard deviation.

aSame lowercase letters indicate lack of statistical difference (Tukey post-hoc test).

bFailure modes: I, adhesive failure in the tooth composite interface; II, cohesive failure in the composite; III, mixed adhesive and cohesive failure in the composite; IV, mixed adhesive and cohesive failure in the tooth.

\section{Discussion}

Successful reattachment of fractured tooth depends on several factors like the storage media, preparation mode, adhesive system, and the materials used for reattachment. ${ }^{8,12,15,23}$ The present study evaluated the fracture strength of fractured incisors restored through fragment reattachment technique with conventional and bioactive flowable composites. The bioactive agent of Activa has dynamic interaction with the tooth structure, and mimics the natural teeth physically and chemically. Therefore, it was hypothesized that this material can establish the integrity and continuity between the two fragments. The current findings showed that the fracture resistance of the teeth reattached with Activa was comparable to the conventional flowable composite. Thus, the first hypothesis was accepted. However, this material is smart and moisture-friendly with dynamic role in the mouth, so it can substitute the older conventional composites without bioactive potential.

Activa is a hybrid material with biologic properties similar to glass ionomer, so it can be used without bonding agent. ${ }^{24}$
Application of the bonding agent is recommended in nonretentive preparations. The present study compared the use of Activa with or without bonding to find if selective etching and self-etching bonding agent could improve the bonding of Activa to dentin and enamel. For specimens without bonding agent, the fracture resistance decreased significantly. Therefore, using adhesive system with Activa is suggested, which is in accordance with the results of Poitevin et al. ${ }^{25}$ Another study also recommended the use of bonding agent in conjunction with self-adhesive composite. ${ }^{26}$

If the exposed dentin is close to the pulp chamber, like what is seen in most cases of crown fracture, self-etch adhesive is more appropriate. ${ }^{27}$ Bonding of the self-etch system involves two adhesion mechanisms: micromechanical interlocking and chemical bond. As formerly mentioned, the 10-MDP functional monomer is capable of forming strong ionic bonds with the calcium of hydroxyapatite crystals remaining around the collagen fibers. ${ }^{11}$ Since mild self-etch adhesive system is not efficient for enamel etching, some researchers suggest selective enamel-etching technique.

In the present study, selective enamel etching was done before bonding agent application. Clearfil SE Bond was 
selected as bonding agent because of the 10-MDP content and its compatibility with dual-curing composite. ${ }^{27}$

Controversies exist among the results of the investigation about using CPP-ACP on the tooth surface before adhesive application. Some studies found that pretreating the enamel with CPP-ACP before etching increases the surface roughness, provides a greater surface area for the adhesive bonding, and improves the interaction of enamel surface with the adhesive system. ${ }^{28-30}$ Applying the CPP-ACP also increases the wettability of the dentin surfaces, thereby creating a high-energy surface and low contact angles, which are usually in favor of mechanical lock and adhesion. ${ }^{31}$

The adhesives that contain phosphoric acid esters have shown better bond strength on the CPP-ACP-treated substrates. The reason is the increased availability of calcium ions, which can chemically bond with the phosphoric acid ester monomers. ${ }^{11,31,32}$ The hydroxyl groups in these monomers can chelate with the calcium ions. ${ }^{18}$ The present study detected that CPP-ACP application prior to Clearfil SE Bond significantly increased the fracture strength of bioactive composite, but the increase was not statistically significant for the conventional composite. Therefore, the second hypothesis was accepted only for the conventional composite. Similar results were achieved by Araújo et $a l,{ }^{33}$ who reported that application of the CPP-ACP paste for 10-MDP-based adhesive system did not increase the bond strength for conventional composite.

In contrary, Adebayo et $\mathrm{al}^{34}$ observed that upon removing the smear layer, the CPP-ACP-containing materials increased the bond strength of self-etch adhesive system.

Jalannavar and Tavargeri ${ }^{32}$ also found that the bond strength increased when the broken fragment was kept in CPP-ACP paste (12-24 hours). These contradictory results can be attributed to the different pretreatment times ( 3 minutes in the present study as recommended by the manufacturer), variety of bonding agents, and presence of the smear layer. In this regard, Yang et $\mathrm{al}^{35}$ believed that application time of 3 minutes was not long enough to induce sufficient remineralization with $\mathrm{CPP}-\mathrm{ACP}$ by forming the substances that occlude the dentinal tubules. Therefore, they suggested longer pretreatment time.

In this study, when Activa was used without bonding in self-adhesive mode, the fracture strength was not influenced by CPP-ACP $(p<0.05)$. According to a study by Shafiei et al, ${ }^{36}$ pretreatment of the dentin with CPP-ACP positively affected the bonding ability of self-adhering materials (resin-modified glass ionomer and self-adhering flowable composite resin). In their study, use of ethylenediaminetetraacetic acid conditioning before the CPP-ACP facilitated deeper penetration of the calcium and phosphate ions into the dentin, without the interfering penetration of acidic monomers of the self-adhesive composite. ${ }^{36}$ Seemingly, the presence of smear layer interferes with the beneficial effect of CPP-ACP on the adhesion capabilities of the self-adhesive composite.

Regarding the failure mode, adhesive failure was the most prevalent failure pattern in the groups without bonding, which correlates with the lower bond strength. The fewer adhesive failures in the pretreated groups might be attributed to the stronger interaction of the tooth substrate and the adhesive.

This study was designed to be done on intact teeth of approximately equal size and age. To overcome this limitation bovine teeth were used, which are proper substitutes for human teeth. ${ }^{37,38}$ Breaking and cutting methods can be used to simulate tooth fracture. In breaking method, adaptation between the remaining fragment and the broken fragment increases the fracture resistance values. ${ }^{37}$ In this study, diamond disc was used to cut the fragments. Thus, the evaluations were exclusively focused on the pure effect of employed reattachment materials without the intervention of adaptation. Another limitation of the study was regarding the mechanical test, which was desirable to be dynamic. Due to lack of access to computerized systems for calculation of surface area, fracture resistance test was done.

The current study was a preliminary study to compare the effect of bioactive and conventional composites on the fracture strength of reattached teeth. However, an ongoing study is being performed to investigate the effect of ion release and the recharging capacity of Activa on improvement and preservation of the bond strength with load cycling and interval application of CPP-ACP on reattached specimens.

\section{Conclusion}

With respect to the present findings, it was concluded that bioactive composite was not superior to the conventional composite for fragment reattachment. However, pretreatment with CPP-ACP improved the resistance to fracture of bioactive composite in case of applying bonding agent, but not the conventional composite. Using bioactive composite in selfadhesive mode without bonding agent led to decreased fracture resistance.

\section{Funding}

The authors thank the Vice-Chancellery of Shiraz University of Medical Sciences for supporting this research (Grant\#19805).

\section{Conflict of Interest}

None declared.

\section{Acknowledgments}

The authors also thank Dr. Vosoughi from the Center for Research Improvement of the School of Dentistry for statistical analysis and Farzaneh Rasouli for improving the use of English in the manuscript.

\section{References}

1 Andreasen JO, Andreasen FM, Andersson L, Crownroot Fractures. Textbook and Color Atlas of Traumatic Injuries to the Teeth. Wiley-Blackwell; 2007

2 Jyothi M, Jyothirmayi B, Sirisha K, Mounika A, Girish K, Sruthi M. Reattachment-conservative management of complicated crown fractures in anterior teeth. Int J Appl Dent Sci 2016;2:10-13

3 Belcheva A. Reattachment of fractured permanent incisors in schoolchildren. J IMAB 2009;14:93-96 
4 Joshi N, Shetty N, Kundabala M. Immediate reattachment of fractured tooth segment using dual cure resin. Kathmandu Univ Med J (KUMJ) 2008;6(23):386-388 (KUMJ)

5 Macedo GV, Diaz PI, De O Fernandes CA, Ritter AV. Reattachment of anterior teeth fragments: a conservative approach. J Esthet Restor Dent 2008;20(1):5-18, discussion 19-20

6 Reis A, Loguercio AD, Kraul A, Matson E. Reattachment of fractured teeth: a review of literature regarding techniques and materials. Oper Dent 2004;29(2):226-233

7 Maia EA, Baratieri LN, de Andrada MA, Monteiro S Jr, de Araújo EM Jr. Tooth fragment reattachment: fundamentals of the technique and two case reports. Quintessence Int 2003;34(2):99-107

8 Worthington RB, Murchison DF, Vandewalle KS. Incisal edge reattachment: the effect of preparation utilization and design. Quintessence Int 1999;30(9):637-643

9 De Santis R, Prisco D, Nazhat SN, et al. Mechanical strength of tooth fragment reattachment. J Biomed Mater Res 2001;55(4):629-636

10 Farik B, Munksgaard EC. Fracture strength of intact and fragment-bonded teeth at various velocities of the applied force. Eur J Oral Sci 1999;107(1):70-73

11 Yoshida Y, Nagakane K, Fukuda R, et al. Comparative study on adhesive performance of functional monomers. J Dent Res 2004;83(6):454-458

12 Farik B, Munksgaard EC, Andreasen JO, Kreiborg S. Fractured teeth bonded with dentin adhesives with and without unfilled resin. Dent Traumatol 2002;18(2):66-69

13 Lo Giudice G, Lipari F, Lizio A, Cervino G, Cicciù M. Tooth fragment reattachment technique on a pluri traumatized tooth. J Conserv Dent 2012;15(1):80-83

14 Wiegand A, Rödig T, Attin T. [Treatment of crown fractured incisors: reattachment instead of restoration?]. Schweiz Monatsschr Zahnmed 2005;115(12):1172-1181

15 Demarco FF, Fay RM, Pinzon LM, Powers JM. Fracture resistance of re-attached coronal fragments-influence of different adhesive materials and bevel preparation. Dent Traumatol 2004;20(3):157-163

16 Shafiei F, Memarpour M, Jowkar Z. Marginal sealing of a porcelain laminate veneer luted with three different resin cements on fluorosed teeth. Int J Esthet Dent. 2017;12(1):60-71

17 Elgamily H, Safwat E, Soliman Z, Salama H, El-Sayed H, Anwar M. Antibacterial and remineralization efficacy of casein phosphopeptide, glycomacropeptide nanocomplex, and probiotics in experimental toothpastes: an in vitro comparative study. Eur J Dent 2019;13(3):391-398

18 Karami M, Shirani F, Kaveh S, Talaee S, Salehi E. Shear bond strength of composite to primary enamel treated with casein phosphopeptide amorphous calcium phosphate using totaletch and self-etch bonding systems. J Islam Dent Assoc Iran 2015;27:2

19 Sauro S, Makeeva I, Faus-Matoses V, et al. Effects of ions-releasing restorative materials on the dentine bonding longevity of modern universal adhesives after load-cycle and prolonged artificial saliva aging. Materials (Basel) 2019;12(5):722

20 Gjorgievska E, Nicholson JW, Iljovska S, Slipper IJ. Marginal adaptation and performance of bioactive dental restorative materials in deciduous and young permanent teeth. J Appl Oral Sci 2008;16(1):1-6

21 Owens BM, Phebus JG, Johnson WW. Evaluation of the marginal integrity of a bioactive restorative material. Gen Dent 2018;66(3):32-36
22 Croll TP, Berg JH, Donly KJ. Dental repair material: a resin-modified glass-ionomer bioactive ionic resin-based composite. Compend Contin Educ Dent 2015;36(1):60-65

23 Shirani F, Sakhaei Manesh V, Malekipour MR. Preservation of coronal tooth fragments prior to reattachment. Aust Dent J 2013;58(3):321-325

24 Rosa WL, Piva E, Silva AF. Bond strength of universal adhesives: a systematic review and meta-analysis. J Dent 2015;43(7):765-776

25 Poitevin A, De Munck J, Van Ende A, et al. Bonding effectiveness of self-adhesive composites to dentin and enamel. Dent Mater 2013;29(2):221-230

26 Doozaneh M, Koohpeima F, Firouzmandi M, Abbassiyan F. Shear bond strength of self-adhering flowable composite and resin-modified glass ionomer to two pulp capping materials. Iran Endod J 2017;12(1):103-107

27 Bruschi-Alonso RC, Alonso RCB, Correr GM, et al. Reattachment of anterior fractured teeth: effect of materials and techniques on impact strength. Dent Traumatol 2010;26(4):315-322

28 Adebayo OA, Burrow MF, Tyas MJ. Effects of conditioners on microshear bond strength to enamel after carbamide peroxide bleaching and/or casein phosphopeptide-amorphous calcium phosphate (CPP-ACP) treatment. J Dent 2007;35(11):862-870

29 LeSage BP. Minimally invasive dentistry: paradigm shifts in preparation design. Pract Proced Aesthet Dent 2009;21(2): 97-101, quiz 102, 116

30 Xiaojun D, Jing L, Xuehua G, et al. Effects of CPP-ACP paste on the shear bond strength of orthodontic brackets. Angle Orthod 2009;79(5):945-950

31 Doozandeh M, Firouzmandi M, Mirmohammadi M. The simultaneous effect of extended etching time and casein phosphopeptide-amorphous calcium phosphate containing paste application on shear bond strength of etch-and-rinse adhesive to caries-affected dentin. J Contemp Dent Pract 2015;16(10):794-799

32 Jalannavar P, Tavargeri A. Influence of storage media and duration of fragment in the media on the bond strength of the reattached tooth fragment. Int J Clin Pediatr Dent 2018;11(2):83-88

33 Araújo DFGd, Borges BCD, Mendes AM, Souza-Junior EJ, Assunção IVd, Santos AJSd. CPP-ACP pretreatment effect on microshear bond strength of simplified etch-and-rinse adhesive systems plus a flowable composite to enamel. J Adhes Sci Technol 2015;29:109-115

34 Adebayo OA, Burrow MF, Tyas MJ. Dentine bonding after CPPACP paste treatment with and without conditioning. J Dent 2008;36(12):1013-1024

35 Yang H, Pei D, Chen Z, Lei J, Zhou L, Huang C. Effects of the application sequence of calcium-containing desensitising pastes during etch-and-rinse adhesive restoration. J Dent 2014;42(9):1115-1123

36 Shafiei F, Derafshi R, Memarpour M. Bond strength of self-adhering materials: effect of dentin-desensitizing treatment with a CРP-ACP paste. Int J Periodontics Restorative Dent 2017;37(6):e337-e343

37 Reis A, Kraul A, Francci C, et al. Re-attachment of anterior fractured teeth: fracture strength using different materials. Oper Dent 2002;27(6):621-627

38 Sarraf P, Nekoofar MH, Sheykhrezae MS, Dummer PMH. Fracture resistance of immature incisors following root filling with various bioactive endodontic cements using an experimental bovine tooth model. Eur J Dent 2019;13(2):156-160 